\title{
DE HOLLANDSCHE IJZEREN SPOORWEG-MAATSCHAPPIJ IN HET JAAR 1883.
}

De lengte der spoorweglijnen, die de Hollandsche IJzeren Spoorwegmaatschappij exploiteerde, werd den 1 November 1883 vermeerderd met het gedeelte Velzen-IJmuiden, lang ruim 3 jkilometers. De totale lengte bedraagt 357 kilometer, verdeeld in $232^{5}$ kilometer eigen lijnen der Maatschappij, 8l kilometer NoordHollandschen Staatsspoorweg en $43^{5}$ kilometer Nederlandsch-Westfaalschen spoorweg.

Behalve deze spoorwegen exploiteerde de Maatschappij nog de volgende Stoomtramwegen:

a. Van Beverwijk naar Wijk-aan-Zee, eigendom der Maatschappij Noordzeebad Wijk-aan-Zee,

b. Van den Haag over Poeldijk naar Naaldwijk on van Poeldijk naar 's Gravezande, eigendom der Westlansche Stoomtramwegmaatschappij;

c. Van Leiden naar Katwijk, eigendom van de Rijnlandsche Stoomtramweg-Maatschappij;

d. Van het station Lichtenvoorde-Groenlo naar Groenlo, eigendom der concessionarissen van die tramlijn, en

e. Van Bussum naar Huizen, eigendom van de StoomtramwegMaatschappij Bussum-Huizen.

De lengte der Stoomtramlijnen is als volgt:

Beverwijk-Wijk-aan-Zee . . . . . . $4.86 \mathrm{KM}$.

Den Haag-Poeldijk-Naaldwijk : . . . . 13.49 n

Poeldijk-'sGravesande . . . . . . . . $5.82 n$

Leiden-Katwijk . . . . . . . . . . 8.67 n

Lichtenvoorde-Groenlo . . . . . . . 4.00 ”

Bussum-Huizen . . . . . . . . $\frac{6.3 n}{43.14 \mathrm{KM}}$

Het gedeelte Loosduinen-Naaldwijk werd geopend 1 Mei 1883, en Poeldijk-'s Gravesande 14 Augustus 1883.

EcoN. 1884. 
De stoomtram Leiden-Katwijk wordt sinds 1 Juni 1883 door de H. IJ S. M. geexploiteerd.

De stoomtrammen Lichtenvoorde-Groenlo en Bussum-Huizen werden respectivelijk 29 Mei en 8 November 1883 geopend.

Door de tentoonstelling te Amsterdam en andere omstandigheden was het getal reizigers zeer groot en bracht het reizigersvervoer $f 447.784$ meer op dan in 1882 . Het goederen-vervoer vooral op de opstelijke lijnen ontwikkelde zich, maar de copcurreptie veroorzaakte, dat de opbrengst niet in gelijke mate toenam. Gedurende den zomerdienst kwam een nachtdienst tot stand naar Belgie over Utrecht. Bij het begin van den winterdienst weigerde de Maatschappij tot exploitatie, om treinen over het gedeelte Rotterdam-Esschen te vervoeren, waardoor geen nachttreinen konden loopen tusschen Amsterdam en Rotterdam, in aapsluiting met Belgie, Frankrijk, Zwitserland en Italie.

In het vorig jaarverslag wezen wij op de vermindering van de opbrengst der bestelgoederen, tengevolge van de invoering der Rijkspakketpost. Over 1883 heeft zich zulks hersteld; brengt men bij deze vermeerdering in rekening de vergoeding van het Rijk aan de Maatschappij voor het vervoer der postpakketten, dan geeft zulks een vermeerdering van opbrengst door deze beide zaken van $f 25.665$.

Het. ijlgoederen-vervoer is wederom achteruitgegaan, en verminderd met $f 4.137$.

Evenals in het vorig jaar is het vervoer van vrachtgoederen zeer toegenomen, en bedroeg $f 180.663$.

Ten gevolge van het verbod van invoer van Hollandsch vee in het buitenland bracht het veevervoer $f 10.213$ minder op, dan in 1882 .

Door het grootere goederenvervoer was het totale bedrag der diverse ontvangsten voor verkoop van drukwerken, bewąargelden, bestelloonen, enz. bijna $f \mathbf{2 0 . 0 0 0}$ hooger, dan in het vorig jaar.

Het zand vervoer voor anderen gaf dit jaar $f 394.864$, dat is $f 50.935$ minder dan in 1882. Het grootste gedeelte diende tot aanleg van den spoorweg Zaandam-Hoorn, welk vervoer thans: is geöindigd.

Op verzoek van de Maatschappij tot exploitatie van Staatsspoorwegen werden gedurende den zomerdienst de personen-treinen dier Maatschappij doorgevoerd van Utrecht tot Amsterdam. De vergoeding van genoemde lijnen aan de H. IJ. \$. M. verminderd met het aan de Maatschappij tot Exploitatie toekomend aandeel uit de opbrengst dier treinen, bedroeg $f \mathbf{1 1 . 2 3 7}$.

De telegraaf bracht $f 857$ meer op dan in 1882 . 
De totale opbrengst was $f 7.055 .656$ of $f 668.220$ meer, dan in het vorig jaar, en de gemiddelde opbrengst per kilometer van alle lijnen $f 19.903$ tegenover $f 18.043$ in 1882 .

De opbréngst per baditiak en per kilometer bedroeg in ronde sommen :

Baanvak. Kilometer-lengte. Opbrengst per kilometer.

\begin{tabular}{|c|c|c|c|}
\hline \multirow[t]{2}{*}{ Deativing. } & \multirow[t]{2}{*}{ lengte. } & \multicolumn{2}{|c|}{ Opbrengst per kilometer. } \\
\hline & & 1882 & 1883 \\
\hline Rotterdain-den Haag & 23 & $f 43130$ & $f 43405$ \\
\hline den Haag-Leiden & 15 & ${ }_{n} 33246$ & n35025 \\
\hline Loiden-Haarlem & 29 & n 23863 & 27000 \\
\hline Haarlem-Amsterdam & 18 & „40070 & n 42579 \\
\hline Amsterdam-Amersfoort & 45 & n 23474 & n 27255 \\
\hline Amersfoort-Zutphen & 60 & 9.9562 & 10995 \\
\hline Zutphen-Winterswijk & 44 & $\eta 6848$ & ^ 7162 \\
\hline Hilversum-Utrecht & 18 & $\eta 9407$ & „ 12868 \\
\hline Haarlem-Uitgeest & 18 & 8054 & $\pitchfork 7641$ \\
\hline Helder-Alkmaar & 42 & $n \quad 4976$ & $₫ 5110$ \\
\hline Alkmaar-Uitgeest & 16 & $" 8571$ & n 8784 \\
\hline Uitgeest-Amsterdam & 23 & 9735 & „11221 \\
\hline
\end{tabular}

Onder deze opbrengst zijn niet begrepen de zoogenaamde diverse baten en telegraaf, in 1883 te zamen $f 656.818$.

- Volgens de exploitatierekening waren de ontvangsten in 1883:

Reizigers. . . . . . . . . . . . . . . $f 4,309.550$

Bagage der Reizigers . . . . . . . . . . . 》 75.510

Bestelgoederen . . . . . . . . . . . . . .

Vrachtgoederen . . . . . . . . . . . . . ${ }_{n} 1,323.221$

IJlgoederen . . . . . . . . . . . . . . . „103.366

Zand . . . . . . . . . . . . . . . . . " 394864

Aandeel in het vervoer van postpakketten . . . . " 31.732

Verkoop van drukwerken, bewaargelden, bestel-

loonen, enz . . . . . . . . . . . . . .

Paarden, vee, rijtuigen. . . . . . . . . . . ” 111271

Telegraaf. . . . . . . . . . . . . . . . ${ }^{n} 14.826$

Opbrengst van eigendommen, buffetten, stationeerende

rijtuigen, enz . . . . . . . . . . . . . $n 165.973$

Opbrengst van zand- en watertreinen, ten behoeve

der exploitatie . . . . . . . . . . . . . , 38.186

Opbrengst van treinen van de Maatschappij tot

Exploitatio . . . . . . . . . . . . . . n 11.237

Totaal. $\cdot \cdot \frac{n}{f 7,055.656}$ 
De gewone uitgaven zijn gesplitst in vier hoofdafdeelingen.

1882

Weg en werken. . . $f 1,013.200$

Tractio en materieel . $, 1,057.700$

Beweging en vervoer. ${ }_{n} 1,067.200$

Algemeene dienst . . $\pi 263.600$

Te zamen. . . . $\bar{f} \overline{3,401.700}$

Van de ontvangsten . $\quad 53.26 \frac{\mathrm{n}}{\mathrm{0}}$
1883

$f 1,048.061$

》 $1,224.691$

$\cap 1,275.100$

$\begin{array}{r}\$ 324.017 \\ \hline 3,871.869\end{array}$

$54.87 \frac{0}{0}$

De gewone kosten van onderhoud van den weg en van de stations zijn hooger geweest dan in het vorige jaar, een gevolg van de periodieke loonsverhooging van de arbeiders en van eene belangrijke vernieuwing van onderlagen op den Oosterspoorweg. Het onderhoud van het tijdelijke station te Amsterdam was vrij duur. Door het invoeren van nachtdienst op den Oosterspoorweg kostte de bewaking van den weg $f 20.000$ meer dan in het vorig jaar. De voornaamste werken die uitgevoerd werden, maar grootendeels niet werden gerekend onder het gewone onderhoud, maar tot de werken van uitbreiding waarmede de waarde van den spoorweg vermeerderd is, en dus niet hierboven onder Weg en werken zijn begrepen, maar volledigheidshalve worden genoemd, waren het bouwen van eenige wachterswoningen, het uitbreiden of het veranderen van het stations-emplacement te Halfweg, Haarlem, den Haag, Delft, Schiedam, Rotterdam, Utrecht, Heer-Hugowaard, Alkmaar, Rietlanden, Ruurlo, Vorden, Lichtenvoorde, enz., het maken van gebouwen te Amsterdam, Delft, Hilversum, Helder, enz., het aankoopen van grond en gebouwen, het maken van een hydraulische kraan te Amsterdam, enz. Behalve deze werken moet nog vermeld worden de spoorweg van Velsen naar IJmuiden. De werken van uitbreiding hebben in 1883 een uitgaaf gevorderd van bijna $f 916.000$; de waarde van sommige zaken is verminderd met $f 191.000$, dus een totale waardevermeerdering van bijna $f$ 725.000. De kosten van tractie en materieel zijn hooger, vooral door de toeneming van het antal locomotief kilometers; evenzoo de kosten van beweging door de buitengewone uitbreiding, die de treindienst heeft ondergaan.

De algemeene dienst kost meer tengevolge van verhooging van tractementen en vermeerdering van personeel.

Volledigheidshalve later wij bier eenige uitgaven der exploitatie volgen. 
Directie en toezicht der baan. . . . . . . . . $f \mathbf{6 4 . 3 1 2}$

Onderhoud van den weg . . . . . . . . . . ${ }^{\circ} 655.172$

Onderhoud der stations en werkplaatsen. . . . . " 223.301

Bewaking van den weg . . . . . . . . . . ${ }_{n} 105.276$

Derectie der werkplaats en der tractie . . . . . ${ }^{n} \quad \mathbf{4 0 . 7 1 4}$

Onderhoud der locomotieven, na aftrek van $f 42.648$ uit de vernieuwings-rekening. . . . . . . . " 190.813

Onderhond der rijtuigen en wagens na aftrek van

$f 88.193$ uit de vernieuwings-rekening. . . . . $\quad$ » 202.033

Bijdrage tot de vernieuwings-rekening voor rollend materieel . . . . . . . . . . . . . . . „ 125.037

Daggelden aan machinisten, stokers, gratificatien, brandstoffen, olie, vet, smeer, waterbezorging voor locomotieven, enz. . . . . . . . . . . 7666.095

Directie van beweging en verroer. . . . . . . $~ 147.407$

Stations en treindienst. . . . . . . . . . . . 7713.389

Goederen-dienst . . . . . . . . . . . . . $\pi^{414.304}$

Traktementen van ambtenaren en andere kosten vau den algemeenen dienst . . . . . . . . . . $n 324.017$

Totaal. . . . $\overline{f 3,871.870}$

Als huur van den spoorweg is betaald voor het gedeelte Stantsspoorweg Amsterdam-Helder $f 117.431$ en voor Zutphen-Winterswijk van de Nederlandsch-Westfaalsche spoorwegmaatschappij $f$ 92.328. Het renteloos voorschot aan laatstgenoemde Maatschappij is verwinderd met $f 3.843$ en bedraagt $f 24.626$.

$\mathrm{De}$ exploitatie der-stoomtramwegmaatschappijen leverde geen voordeelige resultaten op. Aan de creditzijde der winst- en verlissrekening komt eene kleine bate voor van $f 5.508$; het daarin vastgelegde kapitaal bedraagt $f 473.951$. Het rollend materieel op de tramwegen bestond uit 21 tramlocomotieven, 33 personenrijtuigen, 25 goederenwagens en twee veerwagens.

Met het oog op het gering aantal reizigers gedurende de wintermaanden, is de personendienst op Beverwijk-Wijk-aan-Zee den 1 ste November 1883 tot nader aankondiging gestaakt. De opbrengst dekt nauwelijks de exploitatiekosten, on beliep $f 4.29$ per dagkilometer.

De Westlandsche stoomtramweg eindigt aan een afgelegen gedeelte van den Haag en is niet aan den Hollandschen spoorweg aangesloten; de opbrengst per dagkilometer bedroeg $f 9.56^{5}$.

Lichtenvoorde-Groenlo bragt per dagkilometer op $f 5.87$ en de Rijnlandsche Stoomtramweg $f 16.79^{5}$. 
De geheele vereffening van de schade, teweeg gebragt door de op 3 October 1882 te Rotterdam en op 11 Augustus 1882 te Vogelzang plaats gehad hebbende ongelukken en de betaling van enkele kleine calamiteiten in 1883 vereischte het gebruik der rente van de Reservekas waarin op 31 December 1883 een millioen aanwezig was.

Op de balans komt voor als kostende prijs der oude spoorwegen $f 31.218 .149$ en voor den spoorweg Velsen-IJmuiden $f$ 125.732.

De locomotiefrekening is met $\mathrm{f} 890.102$ gestegen door het aanschaffen van nieuwe locomotieven, en de rollend materieel-rekening met $f 668.906$, waarvoor bijgekocht zijn 36 locomotieven, 42 rijtuigen en 157 goederenwagens, terwijl voor het aanbrengen van den Westinghouse-rem besteed is $\mathrm{f} 203.700$.

Meermalen, onder anderen in ons verslag over 1879 (zie jaargang 1880 , bladz. 613 van dit Tijdschrift) hebben wij er op gewezen, dat de Maatschappij indertijd leeningen had gesloten tegen $4 \frac{1}{2}$ en 5 pCt. en het wenschelijk was, om nu geld voor lager rente is te verkrijgen, die leeningen af te lossen en geld tegen lager, rente op te nemen. In de algemeene vergadering van aandeelhouders van 18 Januari 1883 werd de Directie gemachtigd, om een leening van 22 millioen à $4 \mathrm{pCt}$. te sluiten, uit te geven tegen $99 \mathrm{pCt}$., oun de bestaande leeningen te converteeren en tevens geld te verkrijgen voor de nieuwe werken, de aanschaffing van rollend materieel en den aankoop van de aandeelen der Nijmeegsche spoorwegmaatschappij. Deze leening is reeds grootendeels geplaatst. $O p$ de balans zijn de aandeelen der Nijmeegsche spoorwegmaatschappij geboekt op $f 672.900$.

De verdeeling der reizigers naar het aantal voor de verschillende klassen was voor de eerste klasse ongeveer 12 , de tweede 24 en de derde $64 \mathrm{pCt}$. De gemiddelde afgelegde afstand bedroeg voor de reizigers van de eerste, tweede en derde klasse respectivelijk ongeveer 33,32 en 26 kilometer.

De balans over 1883 werd in de algemeene vergadering van aandeelhouders van 12 Mei 1884 goedgekeurd. Het batig slot.werd verdeeld als volgt: $f 24.000$ aan den Raad van administratie, $f 14.550$ voor belooning aan sommige geemployeerden en een dividend van $f 80$ per aandeel van $f 1000$ (waarvan reeds $f 20$ voorloopig was uitgekeerd.)

$\dot{W}_{i j}$ willen niet eindigen zonder een woord over den staatsspoorweg Amersfoort--Nijmegen. Bij de Wet van 12 November 1875 (Staatsblad No. 205) is bepaald, dat voor rekening van den 
Staat verschillende spoorwegen zullen aangelegd worden, onder anderen van Dordrecht langs Gorinchem en Tiel naar Elst, on van Amersfoort lange Rhenen naar Nijmegen. Volgens de tóelichting der Regeering bij de behandeling van dit wetsontwerp moest laatstgenoemde spoorweg worden aangelegd, om in het belang van den handel Amsterdam met den linker-Rijnoever te verbinden en een concurreerende spoorweglijn met den Rijnspoorweg te verkrijgen. Om dit doel het beste te bereiken behoorde Amersfoort-Nijmegen door den Hollandschen IJzeren spoorwegmaatschappij geexploiteerd te worden. Bij de beraadslaging over genoemde wet in de Tweede Kamer vroeg de heer Godefroi, wie Amersfoort-Nijmegen zou exploiteeren. De minister van binnenlandsche zaken Heemskerk antwoordde: ${ }_{n} \mathrm{De}$ heer Godefroi heeft gerraagd, of het mijne meening is, dat de exploitatie van dezen weg in dezelfde handen moet worden gesteld, als de Ooster-spoorweg. Dit is zeer zeker de meéning der Regeering."

Bij gelegenheid van de schriftelijke behandeling van het wetsontwerp tot bekrachtiging eener overeenkomst met de Hollandsche IJzeren spoorwegmaatschappij in de zittingen der Staten-Generaal van $1875-1876$ en $1876-1877$ werd herhaaldelijk het gevoelen ontwikkeld, dat Amersfoort--Nijmegen door de Hollandsche IJzeren spoorwegmaatschappij moest geexploiteerd worden. Wij vinden in de bijlage 48 , zitting 1876-1877 onder anderen het volgende stik, gedagteekend 16 September 1876, en onderteekend door den Mínister van binnenlandsche zaken Heemskerk en den Minister van Finautien van der Heim: "Ten vierde zou wel is waar, de "exploitatie der lijn Amersfoort-Nijmegen op grond van het sub. „d, van Art. 1 der ontworpen overeenkomst met de Exploitatie„Maatschappij $\left(^{*}\right)$ aan deze kunnen worden opgedragen, maar "behalve het finantieele nadeel, dat hieruit voor den Staat voort"vloeit, is er nog een veel grooter nadeel aan verbonden. In het nbelang van den handel, vooral van dien van Amsterdam, is het "wenschelijk, dat deze regtstreeksche verbinding met de midden${ }_{n}$ Duitsche spoorweglijnen zich in ééne hand bevinden met de lijn "van de hoofdstad naar Amersfoort. Dit kan verkregen worden,

(*) Deze overeenkonist is reeds bekrachtigd bij de Wet van 15 November 1876 (St. no. 210). In art. I d. staat, dat de koning aan de Exploitatie-Maatschappij de verplichting kan opleggen, om de spoorrregen te exploiteeren, die de Staat nocht aunleggen of in bezil krijgen, mits de bedoelde wegen aqusluiten aan de door de Maatschappij alsdai geexploiteerde wegen. 
wanneer zij geexploiteerd wordt door de Hollandsche spoorwegnmaatschappij, die in het bezit is van den Oosterspoorweg."

Nadat den 24 October 1876 het genoemde wetsontwerp in de Tweede Kamer was vorworpen, is de Regeering later met de Hollandsche IJzeren spoorwegmaatschappij weer in onderhandeling getreden, die geleid heeft tot de overeenkomst, bekrachtigd bij de Wet van 19 December 1882 (zie bladz. 638 van jaargang 1883 van dit Tijdschrift). Ook toen was de Regering nog steeds voornemens, Amersfoort-Nijmegen door de Hollandsche IJzeren Spoorwegmaatschappij to laten exploiteeren zooals men bij voorbeeld ziet uit de Memorie van antwoord op het Voorloopig Verslag der Tweede Kamer, waar de Minister van Waterstaat Klerck en van Finantion van Lijuden van Saudenburg schrijven: "Ongetwijfeld kan de lijn van Amsterdam over Hilversum naar ${ }_{n}$ Amersfoort nog veel grooter beteekenis erlangen, wanneer de $₫$ lijn Amersfoort-Nijmegon voor het verkeer zal geopend zijn, neen reden te meer, dat an verbrokkeling der exploitatie niet "zou kunnen. worden gedacht."

Bij verschillende gelegenheden hebben Regeering en Vertegenwoordiging het wenschelijke betoogd, dat Amersfoort-Nịmegen geëxploiteerd worde door de Hollandsche IJzeren spoorwegmaatschappij de eigenaren en exploitante van Amsterdam-Amersfoort.

De Maatschappij tot exploitatie van Staatsspoorwegen is steeds overtuigd geweest, dat Amersfoort-Nijmegen door de Hollandsche IJzeren Spoorwegmaatschappij zou geexploiteerd worden. In de gedrukte toelichting van het voorstel van den Directeur-generaal aan de aandeelhouders van de Maatschappij tot exploitatie van Staatsspoorwegen, dato 16 Mei 1876, wijst de Directeur-generaal er op, dat het Bestuur de voorgestelde overeenkomst met de Regeering slechts schoorvoetende aanbeveelt, en dat zulks onder anderen alleen geschiedt, om te voorkomen, dat de Hollandsche IJzeren spoorwegmaatschappij de exploitatie verkrijgt van de spoorwegen Dordrecht-Elst en Nijmegen-Venlo.

Uit deze redenering volgt, dat de Directeur-generaal verwachtte, dat Amersfoort-Nijmegen door de Hollandsche IJzeren spoorwegmaatschappij zou geexploiteerd worden, want anders kon deze geen aanspraak maken op Dordrecht-Elst en op Nijmegen-Venlo, daar zij dan niet aansloten aan de lijnen der Hollandsche IJzeren Spoorwegmaatschappij.

In de zitting der Tweede Kamer van 22 December 1883 wees de ondergeteekende, op het wenschelijke, dat de Regeering eene 
beslissing nam in zake de exploitatie Amersfoort-Nijmegen, die volgens zijn meening a.an de Hollandsche IJzeren spoorwegmaatschappij moest worden opgedragen. Tevens moest men met deze Maatschappij regelen vastatellen, opdat de treinen der Exploitatie-Maatschappij van Utrecht tot Amsterdam door zouden kunnen loopen.

De heeren Reuther en Bahlmann beaamden insgelijks het wenschelijke, dat Amersfoort-Nijmegen door de Hollandsche IJzcren spoorwegmaatschappij zou worden geexploiteerd.

De Minister van Waterstaat, van de Bergh, gaf slechts ontwijkende antwoorden. De zaak bleef rusten tot in de zittingen der Tweede Kamer van 15 en 16 Mei jl. de heer Bahlmann een interpellatie tot de Regeering hield over deze zaak. De heer Bahlman bewees door verschillende aanhalingen, dat de opvolgende Regeeringen steeds voornemens gewcest waren de exploitatie AmersfoortNijmegen aan de Hollandsche IJzeren spoorwegmaatschappij op te dragen. Die meening werd rroeger ook gedeeld door de Exploitatie-maatschappij; tot staving haalde hij aan het jaarverslag der Exploitatie-maatschappij, uitgebracht in de vergadering van 30 Mei 1876, onder voorzitterschap van Jhr. Mr. den Tex, waar men leest: „De aanleg der lijn Amersfoort-Nijmegen zal allerwaar"schijnlijkst het gevolg hebben, dat de zoo kostbare lijn UtrechtnBoxtel van hoofdlijn, waartoe zij bestemd was, zal worden terug"gebracht tot een lijn van secundair belang; zij zal ophouden te „zijn een der groote handelswegen voor Amsterdam naar Zuid"Duitschland via Venlo."

In zijn kwaliteit van lid der Eerste Kamer zeide de heer den Tex den 13den November 1876: „De Nederlandsche Staat, „die ten einde het traject naar Keulen 24 kilometers te verkor"ten, aan de Wetgevende Macht het voorstel doet om de lijn "Amersfoort-Nijmegen te bouwen, terwijl hij daardoor zijne lijn "Utrecht-Venlo tot eene lijn van den tweeden rang verlaagt, is "het dan ook niet te doen, om veel geld te trekken. Aan eene lijn „van 138 kilometers, welke ongeveer 36 millioen gekost heeft, en ${ }_{n}$ waarop de goederen van Duitschland op de geheele lengte bleven, "wordt door den eigenaar zelven eene concurrentie aangedaan, "waardoor hare handelswaarde grootendeels verloren gegaan is."

Na verschillende beschouwingen vroeg de heer Bahlman an de Regeering, primo: of de Hollandsche ijzeren Spoorwegmaatschappij niet de meeste aanspraak kan maken op Amersfoort-Nijmegen, en of niet de goede trouw vordert, dat aan haar de exploitatie worde opgedragen, en secundo: of de Regeering niet van oordeel is, 
dat door de overgave van Amersfoort-Nijmegen aan de ExploitatieMaatschappij, in verband met de concessie-Vrolik een tarief-oorlog zal ontstaan?

De Minister van Waterstaat van den Bergh antwoordde op de eerste vraag ontkennend; door de afstemming op 24 October 1876 der overeenkomst was de Regeering geheel rrij geworden. Naar aanleiding der tweede vraag, verklaarde de Minister, dat deze niet zoo dadelijk te beantwoorden was, en van verschillende omstandigheden afhing.

Vervolgens zeide de Minister, dat er eigenlijk geen lijn Amersfoort-Nijmegen was, maar wel! vier vakken, als: AmersfoortKesteren, Kesteren-Valburg, Valburg-Ressen en RessenNijmegen.

Omtrent A'mersfoort-Kesteren is de Regeering vrij: KesterenValburg is overenkomstig Art. 1.c. der Overeenkomst van $\frac{24}{2} \frac{4}{5}$ Mei 1876 (wet van 15 November 1876) met de Exploitatie-maatschappij aan die Maatschappij in gebruik' gegeven. Een beding omtrent medegebruik bestaat niet.

Van het valk Valburg-Ressen is bij K. B. van 26. September 1882, No. 13 alleen het mede-gebruik aan de Exploitatie-Maatsohappij! gegeven: Het vak Ressen-Nijmegen maakt een gedeelto uit van den spoorweg Arnhem-Nijmegen; die zonder eenig voorbehoud aan de Eixploitatie-Maatschappij is overgegaan. Wil men alzoo, dat er een lijn Amersfoort-Nijmegen zij, dan moet, ingevolge Art. 5 der wet van 9 April 1875 (St. No 67) het medegebruik van de gedoelten Kestieren-Valburg en Ressen-Nijmegen bij Koninklijk besluit worden gelast. De Exploitatie-Maatischappij heeft dan reoht: op sehadeloosstelling. De Exploitatie-Maatschappij" is in zekeren zin de associé van den Staat, en dientengevolge heeft. do Minister van Finantien meer dan de Minister van Waterstaat' er belang bij: De Hollandsche IJzeren Spoorwegmaatschappij exploiteertevenwel ook eenige Staatsspoorwegen. Het is wenschelijk, dat er van Amsterdam eene spoorwegverbinding, zooveel mogelijk in ééne hand zij naar de Duitsehe grens over Nijmegen, en dat de Exploitatio-maatschappij een terminus krïge te Amsterdam. Naar de middelen om die oplossing te vinden, zal de Regeering zoeken.

$\mathrm{Na}$ den Minister' van Waterstaat voerden nog verschillende lèden het woord; men deed het wenschelijke uitkomen om AmersfoortNijmegen' in exploitatie te geven aan de Hollandsche IJzeren spoorwegimaatschappij. Even als in andere landen, b.v. in Frankrijk, moest aan iedere spoorwegmaatschappij een bijzondère' werkkring g' 
worden gegeven, een zeker gedeelte van het land, dat voor een bijzonder doel door zulk een maatschappij moest bediend worden.

De Exploitatie-Maatschappij is eigenaardig bestemd voor den handel van Rotterdam en Amsterdam met Belgie en Frankrijk en Rotterdam met Duitschland; wanneer die Maatschappij al het mogelijke doet, om dien handel te bevorderen, heeft zij genoeg werk. Een weg van Amsterdam naar Duitschland heeft zij niet noodig, wel het recht, om haar treinen door te mogen laten rijden naar Amsterdam.

De Hollandsche IJzeren spoorwegmaatschappij is, als het ware, aangewezen, om den handel van Amsterdam met Duitschland krachtig te bevorderen. De Kamers van Koophandel van Amsterdam en Nijmegen en andere collegien hebben daarom aangedrongen op de exploitatie van Amsterdam-Nijmegen door die Maatschappij.

Naar aanleiding van den aankoop van aandeelen der Nijmeegsche spoorwegmaatschappij door de Hollandsche werd er op gewezen, dat laatstgenoemde met 1 ' April 1885 het gedeelte Nijmegen tot de Duitsche grenzen zal exploiteeren. Wanneer de Hollandsche IJzeren spoorwegmaatschappij exploiteert Nijmegen-Duitsche grens en Amersfoort-Amsterdam heeft zij volgens art. 5 der wet van 9 April 1875 (St. No. 67) het regt, om libre parcours te vragen van Nijmegen naar Amersfoort.

De bedoeling is geweest, om van af Kesteren twee banen naast elkander te leggen, één voor Dordrecht-Elst en één voor Amersfoort-Nijmegen, ten einde ééne doorloopende lijn AmersfoortNijmegen te verkrijgen-en alzoo een onafgebroken vervoer tusschen Amsterdam en Duitschland via Nijmegen. De wet van 12 November 1875 (St. No. 205) zegt uitdrukkelijk, dat voor rekening van den Staat zal worden aangelegd een spoorweg van Amersfoort langs Rhenen naar Nijmegen; als deze spoorweg niet is gemaakt, behoort de uitvoerende macht te zorgen, dat die nog tot stand kome. De onteigeningswet van 8: Mei 1878 (St. No. 50) noemt den spoorweg van Dordrecht naar Kesteren, terwijl de onteigeningswet van 8 Mei 1878 (St. No. 51) uitdrukkelijk spreekt van den spoorweg van Amersfoort naar Nijmegen; alles, wat ten oosten van Kesteren ligt, is onteigend ten name van den spoorweg Amersfoort-Nijmegen. Het is daarom verkeerd geweest, dat het gedeelte Kesteren-Valburg in zijn geheel zonder voorbehoud voor den spoorweg Amersfoort-Nijmegen aan de Exploitatie-maatschappij is overgedragen. Op verzoek van eenige leden beloofde de Minister van Waterstaat, dat bij het stuk, betreffende de overgave door den Staat 
aan de Exploitatie-Maatschappij aan de Tweede Kamer zou zenden.

Een langdurig debat had plaats over het wenschelijke, dat door de Wet zou geregeld worden de exploitatie van AmersfoortNijmegen. Sommigen wezen er op, dat ten gevolge der goedkeuring door de wetten van 15 November (St. No. 210) en van 19 December 1882 (St. No. 241) der Overeenkomsten met de Exploitatiemaatschappij en met de Hollandsche IJzeren spoorwegmaatschappij aan den Koning reeds de bevoegdheid is gegeven, om aan deze maatschappijen de exploitatie van Amersfoort-Nijmegen op te dragen.

Met 33 tegen 29 stemmen werd ten slotte een motie van den heer Bahlman aangenomen, luidende: „De Kamer van oordeel, dat omtrent de uitgifte in exploitatie van den Staatsspoorweg van Amersfoort langs Rhenen naar Nijmegen wettelijke voorziening wenschelijk is, gaat over tot de orde van den dag."

Het schijnt, dat men niet, zooals beboorde, van Kesteren tot Valburg den spoorweg zoodanig heeft aangelegd, dat hij geschikt is voor twee banen, één van Dordrecht naar Elst en één van Amerfoort naar Nijmegen maar slechts voor één baan. Aan de Exploitatie-Maatschappij is bij de wet opgedragen de exploitatie van Dordrecht-Elst; bij de overgave van Kesteren-Valburg heeft men dat vak spoorweg in zijn geheel aan de Exploitatie-maatschappij gegeven, zonder het recht voor te behouden, dat het ook mocht gebruikt worden door den exploitant van Amersfoort-Nijmegen. Feitelijk is alzoo geen weg Amersfoort-Nijmegen gemaakt, zooals de wet voorschrijft. Wanneer men in het vervolg treinen wil laten loopen van Amersfoort naar Nijmegen, dan kan men alleen beschikken over de twee gedeelten Amersfoort-Kesteren en Valburg-Ressen.

Om van Kesteren naar Valburg en van Ressen naar Nijmegen te rijden, zal men ingevolge art. 5 der wet van 9 April 1875 (St. no. 67) het medegebruik dier spoorwegvakken moeten opleggen Voor dat medegebruik heeft de Exploitatie-maatschappij recht op schadeloosstelling. Had men het medegebruik voor AmersfoortNijmegen voorbehouden, dan zou men het gratis hebben gekregen. Dit is vergeten, en nu zal de schatkist direct of indirect het verzuim moeten lijden. Wij herinneren dat het stuk Kesteren-Valburg in exploitatie is gekomen 1 November 1882 , toen de heer Klerck Minister van Waterstaat was, en dat Arnhem-Nijmegen is geopend den 15n Junij 1879 onder het bestuur van den minister van Waterstaat Tak van Poortvliet.

J. J. VAN KERKWIJK. 